\title{
The Migration and Transformation of Heavy Metals in Sewage Sludge during Hydrothermal Carbonization Combined with Combustion
}

\author{
Meng Liu $\mathbb{D}^{1,2}$ Yufeng Duan, ${ }^{1}$ Kagiso Bikane, ${ }^{2}$ and Liang Zhao ${ }^{3}$ \\ ${ }^{1}$ Key Laboratory of Energy Thermal Conversion and Control of Ministry of Education, Southeast University, Nanjing 210096, China \\ ${ }^{2}$ Department of Chemical Engineering, Imperial College London, SW7 2AZ, UK \\ ${ }^{3}$ College of Materials Science and Engineering, Nanjing Forestry University, Nanjing 210037, China
}

Correspondence should be addressed to Meng Liu; lmubear@seu.edu.cn

Received 27 January 2018; Revised 16 April 2018; Accepted 5 June 2018; Published 27 June 2018

Academic Editor: Zhang Lei

Copyright (c) 2018 Meng Liu et al. This is an open access article distributed under the Creative Commons Attribution License, which permits unrestricted use, distribution, and reproduction in any medium, provided the original work is properly cited.

The migration and transformation behaviors of heavy metals (HMs), including $\mathrm{Cr}, \mathrm{Mn}, \mathrm{Ni}, \mathrm{Cu}, \mathrm{Zn}, \mathrm{As}$, $\mathrm{Cd}$, and $\mathrm{Pb}$, during the hydrothermal carbonization (HTC) of sewage sludge (SS) were investigated. The immobilization of HMs during the combustion of solid residual (SR) produced from HTC of SS was also analyzed. With increasing HTC temperature and residence time, the majority of HMs (except As) accumulated in the SR. The residual rate of As in the SR decreased from $73.95 \%$ to $56.74 \%$ when the residence time was increased from $\mathrm{th}$ to $3 \mathrm{~h}$ and reduced significantly from $73.95 \%$ to $37.48 \%$ when the temperature increased from $220 \circ \mathrm{C}$ to $280 \circ \mathrm{C}$, implying that numerous arsenic compounds dissolved into liquid phase products. Although the HTC process has a positive influence on the transformation of HMs from weakly bound fractions to the more stable fractions, the exchangeable and reducible fractions of $\mathrm{Mn}, \mathrm{Zn}, \mathrm{As}$, and $\mathrm{Cd}$ in the SR were still high. In addition, the leached amounts of $\mathrm{Zn}$ and As were high (14.61 and $6.16 \mathrm{mg} / \mathrm{kg}$, respectively) and showed a high leaching risk to the environment. An increase in HTC temperature and residence time led to an increase of the residual rate of HMs in the combustion residual of SR, implying that the HTC process promotes the stabilization of HMs in the combustion process.

\section{Introduction}

Sewage sludge (SS) is a great potential energy resource and has attracted wide attention as a subject of research. However, it contains high concentrations of pollutants, including pathogenic bacteria, heavy metals (HMs), and toxic organic compounds [1, 2]. Various sludge-to-energy technologies, such as fertilization, anaerobic digestion, carbonization, pyrolysis, gasification, and combustion, have been developed for the recovery of useful energy from SS [3-6]. From the energetic, economic, and environmental points of view, combustion or co-combustion of SS with other solid waste using present equipment is a viable technique of dealing with the sludge instead of land-filling disposal [7]. However, the SS must be dehydrated to improve the net energy input during the combustion process. The dehydration process requires substantial amounts of heat, thereby increasing the economic burden. Hydrothermal carbonization (HTC) is a process whereby sludge can be converted into high-density solid fuel under mild temperatures and pressures [8-10]. In addition, waste heat from the HTC process can be used to preheat the raw materials and improve the recovery of energy [11, 12]. Zhao et al. [11] demonstrated that, under mild conditions $\left(200^{\circ} \mathrm{C}, 30 \mathrm{~min}\right)$, energy recovery from sludge via the HTC process is more than $50 \%$, showing better performance than the mechanical dewatering technology. During the HTC process, copious amounts of toxicity organics are decomposed and the contents of $\mathrm{S}, \mathrm{N}$, and $\mathrm{Cl}$ are reduced. Moreover, some HMs are stabilized in the solid residual (SR) [2,13-18]. Therefore, HTC of SS for high-density and clean solid fuel preparation is a promising technology.

Influences of the HTC reaction conditions, including reaction time, temperature, and dewatering time, on the physicochemical properties of solid, liquid, and gas phase products have been widely investigated to explore the HTC 
TABLE 1: Physicochemical characteristic of SS before and after HTC.

\begin{tabular}{|c|c|c|c|c|c|c|c|c|c|c|c|c|c|}
\hline \multirow{2}{*}{ Samples } & \multicolumn{5}{|c|}{ Ultimate analysis/wt.\% } & \multicolumn{4}{|c|}{ Proximate analysis/wt.\% } & \multirow{2}{*}{$\begin{array}{l}\mathrm{HHV}^{2)} \\
(\mathrm{kJ} / \mathrm{kg})\end{array}$} & \multirow{2}{*}{$\begin{array}{c}\text { Moisture } \\
\text { content of } \mathrm{SR}^{3)} \\
(w \mathrm{w} . \%)\end{array}$} & \multirow{2}{*}{$\begin{array}{c}\mathrm{pH} \\
(\mathrm{WL})\end{array}$} & \multirow{2}{*}{$\begin{array}{c}\mathrm{NH}_{4}{ }^{+}-\mathrm{N} \\
(\mathrm{mg} / \mathrm{L}) \\
(\mathrm{WL})\end{array}$} \\
\hline & $\mathrm{C}_{\mathrm{ad}}$ & $\mathrm{H}_{\mathrm{ad}}$ & $\mathrm{N}_{\mathrm{ad}}$ & $\mathrm{S}_{\mathrm{ad}}$ & $\mathrm{O}_{\mathrm{ad}}{ }^{1)}$ & $\mathrm{M}_{\mathrm{ad}}$ & $\mathrm{V}_{\mathrm{ad}}$ & $\mathrm{FC}_{\mathrm{ad}}$ & $\mathrm{A}_{\mathrm{ad}}$ & & & & \\
\hline SS & 20.13 & 4.61 & 4.68 & 1.73 & 12.41 & 9.54 & 39.66 & 3.90 & 46.90 & 10.11 & - & ND & ND \\
\hline SS-220-1h & 23.87 & 3.45 & 3.49 & 1.12 & 7.71 & 1.95 & 32.74 & 6.90 & 58.41 & 10.31 & 64.90 & 8.70 & 1734 \\
\hline SS-220-2h & 23.21 & 3.06 & 2.95 & 1.44 & 5.57 & 1.86 & 28.86 & 7.37 & 61.91 & 9.78 & 62.50 & 8.90 & 1773 \\
\hline SS-220-3h & 23.65 & 3.14 & 2.82 & 1.82 & 5.28 & 1.59 & 29.37 & 7.34 & 61.70 & 10.06 & 59.35 & 9.00 & 1825 \\
\hline SS-250-1h & 25.26 & 2.93 & 2.32 & 1.36 & 1.85 & 1.54 & 26.61 & 7.11 & 64.74 & 10.67 & 52.30 & 9.20 & 2005 \\
\hline SS-280-1h & 26.69 & 2.64 & 2.16 & 0.87 & 0.28 & 1.34 & 25.07 & 7.47 & 66.02 & 11.28 & 48.50 & 9.50 & 2245 \\
\hline
\end{tabular}

${ }^{1)} \mathrm{O}(\%)=100 \%-(\mathrm{C} \%+\mathrm{N} \%+\mathrm{H} \%+\mathrm{S}+\% \mathrm{M} \%+\mathrm{A} \%)$; ad-air dry basis.

${ }^{2} \mathrm{HHV}$, higher heating value. Calculated was according to Channiwala and Parikh [25].

${ }^{3)}$ Moisture content of SR after filtration and before drying.

mechanism of SS [7-15]. Furthermore, the optimized operation conditions were also obtained from previous studies. In recent years, several researchers have studied the migration and transformation behaviors of HMs during the HTC of SS [2, 16-21]. They mainly focused on the three aspects of the transformation of HMs. (1) The redistribution of HMs in the solid and liquid phase products: after HTC process, most HMs in the SS accumulate in the SR whilst minute amounts of HMs are released into liquid phase products. Additionally, as the temperature is increased, the quantity of HMs released into liquid products increases due to the extraction and decomposition effects of organics and minerals materials. Shi et al. [17] demonstrated that the quantity of HMs released into liquid was only $1.3 \%$, with $\mathrm{Cr}, \mathrm{Ni}$, and $\mathrm{Cu}$ constituting the largest portion of the released $\mathrm{HMs}$ at $200^{\circ} \mathrm{C}$. However, Wang et al. [19] found that the quantity of HMs released into liquid phase products was lower than 19\%. (2) The chemical fractions and speciation of HMs: although different HMs show different transformation behaviors of chemical fractions, the HTC process may have a positive effect on the migration of HMs from bioavailable fractions into the more stable fractions. Shi et al. [17] found that the concentrations of acid soluble/exchangeable and reducible fractions of $\mathrm{HMs}(\mathrm{Zn}$, $\mathrm{Cd}, \mathrm{Pb}, \mathrm{Cr}, \mathrm{Ni}$, and $\mathrm{Cu}$ ) in the SR decreased whilst the residual fraction increased when the HTC temperature was increased. This suggested that the weaker bound fraction of HMs was transformed into the more stable bound fraction. However, Wang et al. [19] found that the acid soluble/exchangeable and reducible fractions of $\mathrm{Zn}, \mathrm{Ni}$, and $\mathrm{Cd}$ in the SR were high, presenting potential risk to the environment. (3) The changes in the leaching characteristics of HMs: after the HTC process, the leachable amounts and leaching rate of HMs were reduced, indicating a reduction of the leaching toxicity of HMs in the SR. However, the leaching percentages of $\mathrm{Zn}, \mathrm{Ni}$, and Cd in the SR were still high and showed a considerable risk to the environment [19]. From the aforementioned works, the HTC process reduces the toxicity and improves the stabilization of HMs in the SR, but the transformation behaviors of HMs is significantly different, even some HMs still pose a high risk to the environment after HTC process. Considering the difference in the properties of SS and the effect of operation conditions on the transformation of HMs, the detailed mechanism of HTC influences the distribution and chemical speciation transformation of HMs in the SS requires further investigation.

Combustion of SR produced from the HTC of SS is considered a promising approach to convert sludge to energy, particularly the cocombustion with other solid fuels [22-24]. After the HTC process, SR showed a lower activation energy and preexponential factor. More than $60 \%$ of nitrogen and sulfur within SS can be removed, making it suitable for use in the combustion equipment $[14,22]$. The transformation and immobilization behaviors of HMs during the combustion of SR produced from HTC of SS are crucial for the reduction of HMs emissions in the combustion process. However, no related studies were reported. Researchers [19] have only investigated the transformation behaviors of HMs in the pyrolysis of SR produced from HTC of SS. They found that the ecotoxicity of HMs in the pyrolysis residual reduced and the HMs could be migrated from bioavailable fractions to the more stable fractions.

In this work, the HTC reaction temperatures and residence times are considered systematically to investigate the distribution and chemical speciation transformation behaviors of HMs in the HTC of SS. Additionally, the immobilization characteristics of HMs during the combustion of SR produced from HTC of SS were analyzed.

\section{Experimental}

2.1. Materials. Dewatered municipal SS with the moisture content of 84.5 wt.\% was obtained from a wastewater treatment plant in Nanjing, China. All the samples were sealed in a glass beaker and kept in a refrigerator at $4^{\circ} \mathrm{C}$. The fuel characteristics of air dry basis raw SS are shown in Table 1. Raw SS has a high ash content (46.9 wt.\%), low fixed carbon content (3.9wt.\%), and an HHV (10.11kJ/kg). Additionally, the elemental contents of C, H, N, S, and $\mathrm{O}$ are 20.13, 4.16, 4.68, 1.73 , and $12.41 \mathrm{wt} \%$, respectively.

2.2. Experiment Procedure of HTC. All HTC experiments were carried out in a batch-type reactor with a volume of $1 \mathrm{~L}$. The schematic of reactor is shown in Figure 1. The reactor was heated by an electric furnace and the reaction 


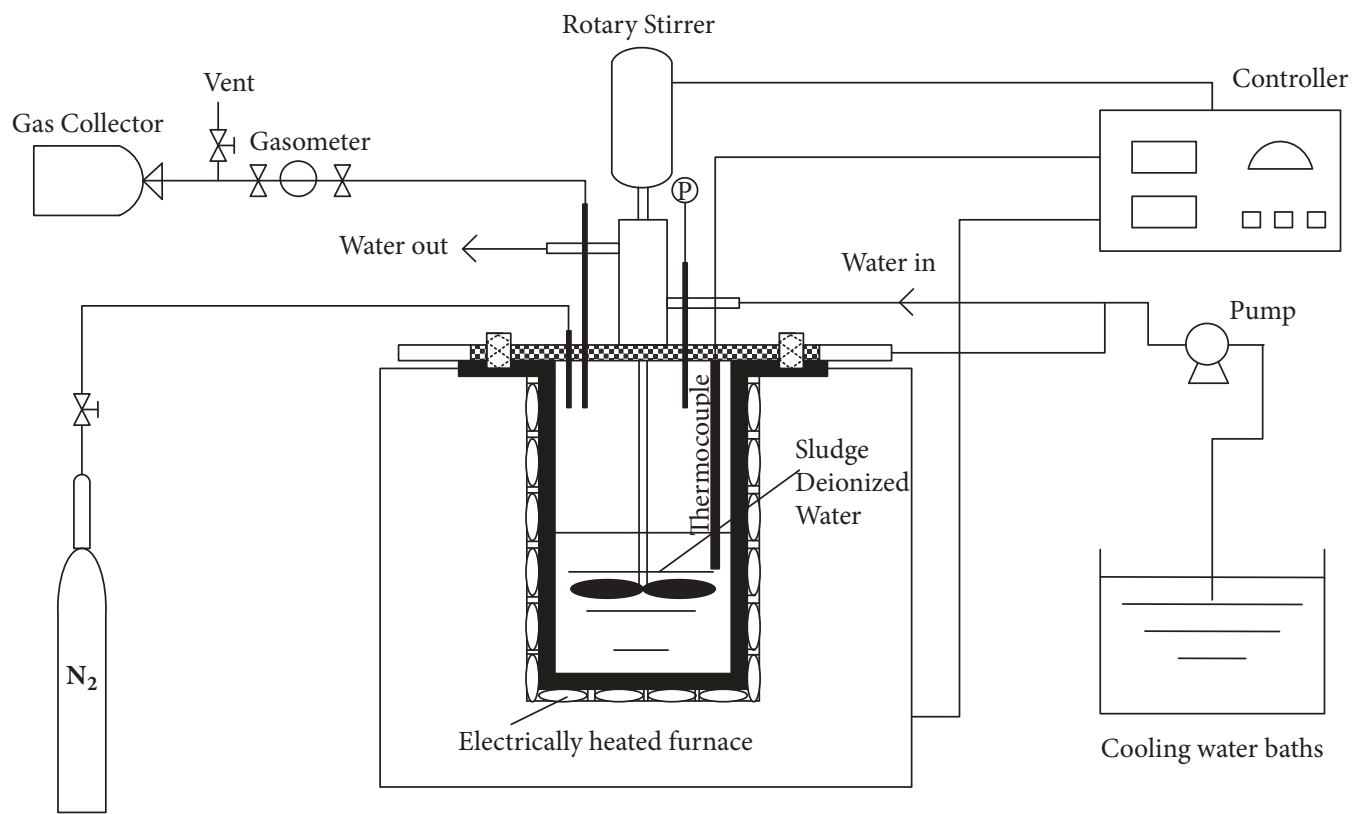

FIGURE 1: Schematic figure of hydrothermal batch-type reactor.

temperature was controlled by a PID control unit. During each experiment, $500 \mathrm{~g}$ of SS and $100 \mathrm{~g}$ of deionized water were fed to the reactor, and the air in the reactor was discharged using high-pressure pure nitrogen. The reaction temperature (i.e., 220,250 , and $280^{\circ} \mathrm{C}$ ) was attained at a heating rate of $5^{\circ} \mathrm{C} / \mathrm{min}$ and the residence times investigated were 1,2 , and $3 \mathrm{~h}$, respectively. The mixer was stirred at 700 rpm to maintain the homogeneity of the reaction. After the reaction, the reactor was rapidly cooled to room temperature using running water. The waste liquid (WL) and SR were collected from the reactor and subsequently separated by suction filtration. When the filtration step was complete, the SR was dried at $105^{\circ} \mathrm{C}$ for $2 \mathrm{~h}$ and ground into fine particles (less than $200 \mu \mathrm{m}$ ) for further analysis. The WL was then placed in a refrigerator at $4^{\circ} \mathrm{C}$. All HTC experiments were carried out three times to ensure the accuracy of data. Operating conditions were labeled using a format of "SS-Xxx$\mathrm{xx}$ ", where " $\mathrm{xxx}$ " is the reaction temperature and " $\mathrm{xx}$ " is the reaction time. For example, "SS-220-1h" represents the HTC of SS at $220^{\circ} \mathrm{C}$ for $1 \mathrm{~h}$.

2.3. Fractionation Procedure of HMs. Speciation of HMs in SS and SR was investigated using the three-step BCR sequential extraction procedure [26]. Four fractions of HMs were extracted, including an acid soluble/exchangeable fraction (F1), a reducible fraction (F2), an oxidizable fraction (F3), and the residual fraction (F4). Detailed steps of the BCR method are reported in the previous studies [26]. For F1 F3, the suspension was collected after the centrifugation step at $10000 \mathrm{rpm}$ for $20 \mathrm{~min}$ and diluted to a constant volume with $2 \% \mathrm{HNO}_{3}$. Fine particles were removed by filtration and dissolved organics were degraded by digestion using $\mathrm{H}_{2} \mathrm{O}_{2}$ and concentrated $\mathrm{HNO}_{3}$. The $\mathrm{F} 4$ fraction and the total amounts of HMs in SS and SR were extracted by digestion with aqua regia solution and subsequently heated on a hot plate. All digestion solutions were filtered and stored in a refrigerator at $4^{\circ} \mathrm{C}$ prior to ICP-MS analysis.

2.4. Leaching Test. The toxicity characteristic leaching procedure (TCLP) has been widely used to evaluate the leach ability of HMs in the SS and SR [27]. TCLP leachates of SR were conditioned using the acetic acid solution ( $\mathrm{pH}$ 2.88 , liquid/solid ratio $=20: 1)$ and were subsequently shook at $200 \mathrm{rpm}$ for $18 \mathrm{~h}$. After centrifugation and filtration, the samples were digested with $\mathrm{H}_{2} \mathrm{O}_{2} / \mathrm{HNO}_{3}$ to remove dissolved organics.

2.5. Analysis. The ultimate and proximate analysis of the SS and SR were determined using Elemental Analyzer (LECOCHNS 932, USA) and an Infrared Rapid Analyzer (5EMACIII, China), respectively. The samples' calorific value was determined using the adiabatic bomb calorimetric method. The HMs content was measured using an ICP-MS (PerkinElmer Elan 9000, LabX, Canada). The composition of elements and minerals in the SS and SR was analyzed by XRF (ARL QUANTX, Thermo Fisher, USA) and XRD (Smartlab 3, Japan), respectively. The ammonia nitrogen in the WL was analyzed with a continuous flow analyzer (AutoAnalyzer3, SEAL).

2.6. Combustion Condition. The combustion process of SS and SR was conducted in a Thermo Gravimetric Analyzer (SETSYS-1750CSEvol, France). The reaction temperature and heating rate were set at $900^{\circ} \mathrm{C}$ and $20^{\circ} \mathrm{C} / \mathrm{min}$, respectively. $\mathrm{O}_{2} / \mathrm{N}_{2}$ (volume 1:4) was used to simulate air atmosphere, and the total flow rate was $50 \mathrm{ml} / \mathrm{min}$. The mass of solid samples was accurately kept at $10 \mathrm{mg}$ for each experiment. The combustion residual was collected for digestion using 
$\mathrm{HCl}, \mathrm{HNO}_{3}, \mathrm{HF}$, and $\mathrm{HClO}_{4}$, successively. After digestion, the liquid samples were sent to an ICP-MS to measure the content of HMs. Each combustion experiment was carried out three times to obtain accuracy data.

\section{Results and Discussion}

3.1. Physicochemical Properties of SR after HTC. Table 1 shows the physicochemical properties of SS before and after HTC. After the HTC process, the moisture content and volatile matter reduced significantly whilst the fixed carbon and ash content increased, implying that the HTC process has a positive effect on the fuel characteristics of SS. In addition, the moisture and oxygen content of SR reduced from 1.95 wt.\% and 8.83 wt. \% to 1.34 wt.\% and 0.35 wt.\%, respectively, when the temperature was increased from 220 to $280^{\circ} \mathrm{C}$. This suggests that the dehydration of sludge significantly occurs during the HTC process. The characteristics presented above led to a slight increase of the HHV of SR. After filtration and before drying, the moisture of SR reduced from $64.9 \mathrm{wt} \%$ to $48.5 \%$ when the reaction temperature was increased from 220 to $280^{\circ} \mathrm{C}$. This observation is associated with the decomposition of protein, polysaccharide, and other macromolecule organic compounds [25, 28]. Moreover, an increase in the reaction temperature from 220 to $280^{\circ} \mathrm{C}$ led to an increase of the $\mathrm{WL} \mathrm{pH}$ value from 8.7 to 9.5. During the HTC of SS, the concentration of ammonium nitrogen organics in the WL increased significantly when the reaction temperature increased. This was attributed to the breakage of $\mathrm{N}$-containing functional groups [29]. This is consistent with the concentration of $\mathrm{NH}_{4}{ }^{+}-\mathrm{N}$ in the WL shown in Table 1 . It can be observed that the concentration of $\mathrm{NH}_{4}{ }^{+}-\mathrm{N}$ in the WL increased significantly from 1734 to $2245 \mathrm{mg} / \mathrm{L}$ when the temperature was increased from 220 to $280^{\circ} \mathrm{C}$. Based on the results of Table 1, the influence of reaction temperature on the fuel quality improvement of HTC of SS is greater than that of the reaction residence time.

\subsection{HMs Concentrations and Redistribution in the SR and}

$W L$. It is well known that hydrothermal treatment, including hydrothermal carbonization [17-19], hydrothermal liquefaction [30-32], and hydrothermal gasification [33], has a significant effect on the transformation of HMs in the SS. The total concentrations of $\mathrm{Cr}, \mathrm{Mn}, \mathrm{Ni}, \mathrm{Cu}, \mathrm{Zn}, \mathrm{As}, \mathrm{Cd}$, and $\mathrm{Pb}$ in the SS and SR are shown in Figure 2. As seen from Figure 2, the considerable amounts of $\mathrm{Mn}$ and $\mathrm{Zn}$ were present; however, relatively low concentrations of $\mathrm{Cr}, \mathrm{Cu}, \mathrm{As}$, and $\mathrm{Pb}$ were observed in the SS. After the HTC process, nearly all the HMs concentrations increased with an increase in reaction temperature and residence time, particularly for $\mathrm{Mn}$ and $\mathrm{Zn}$. In addition, there was a significant increase for $\mathrm{Cu}$ at $280^{\circ} \mathrm{C}$. However, the concentration of As decreased slightly with an increase in temperature and residence time, suggesting that some of the arsenic compounds were dissolved into liquid phase products after the HTC process. From Figure 2, HMs seems to be effectively accumulated in the SR after the HTC process, which is closely related to the physical structures of heavy metal crystal and the condition of HMs under certain temperatures and pressures.

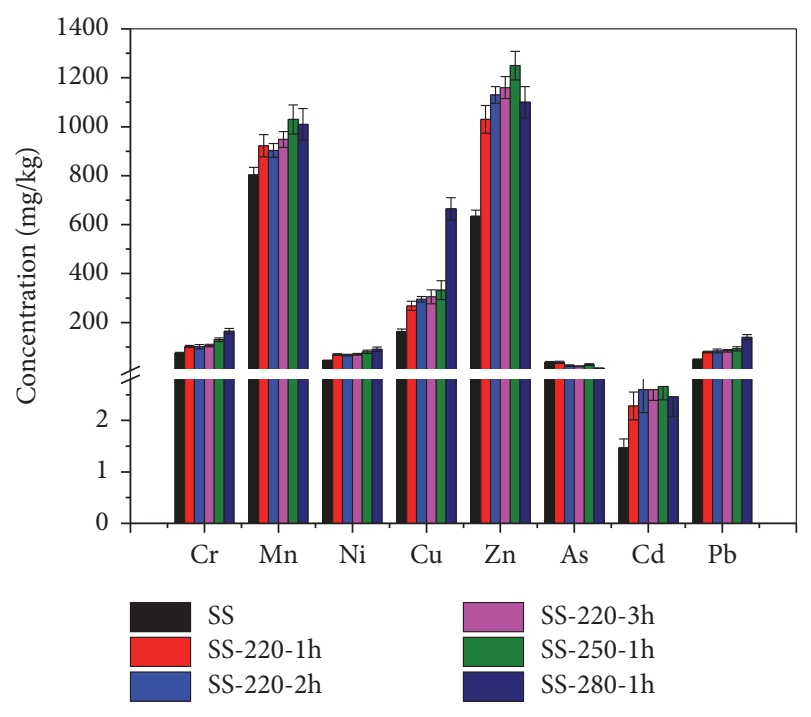

FIGURE 2: Concentrations of HMs in SS and SR.

Since the HTC of sludge is always conducted at low temperature (less than $350^{\circ} \mathrm{C}$ ), the concentration of $\mathrm{HMs}$ in the gas phase products is extremely low and is usually not analyzed. The transformation and stabilization effects of HMs exist simultaneously during the HTC process, resulting in the redistribution of HMs in the solid and liquid phase products. The residual rate of HMs is a parameter that determines the distribution behaviors of HMs during the HTC or combustion process. It can be calculated using the flowing equation:

$$
R_{\mathrm{c}}=\frac{C 2_{\mathrm{x}} \times m_{2}}{C 1_{\mathrm{x}} \times m_{1}} \times 100 \%
$$

where $R \mathrm{c}$ is the residual rate of HMs in the HTC/combustion SR; $\mathrm{x}$ is the type of heavy metal; $C 2_{\mathrm{x}}$ is the total concentration of $\mathrm{x}$ in the SR; $m_{2}$ is the mass of solid residual $(\mathrm{kg}) ; C 1_{\mathrm{x}}$ is the total concentration of $x$ in the raw samples $(\mathrm{mg} / \mathrm{kg}) ; m_{1}$ is the mass of raw samples $(\mathrm{kg})$.

The residual rate of HMs in the SR and WL is presented in Table 2. The results indicate that HTC process seems to have some positive effect on the release of HMs from the solid into liquid phase products. This might be due to the decomposition of extracellular polymeric substances, resulting in breakage of weaker bonded of HMs [17, 19, 21]. As seen from Table 2, different HMs show different released behaviors based on the reaction temperature and residence time. The residual rates of $\mathrm{HMs}$ in the SR products, $\mathrm{Mn}, \mathrm{Ni}, \mathrm{Zn}$, and As, reduced with an increase in the reaction temperature and residence time. The residual rate of As in the SR decreased significantly from $73.95 \%$ to $37.48 \%$ when the temperature was increased from 220 to $280^{\circ} \mathrm{C}$ and reduced from $73.95 \%$ to $56.74 \%$ when the residence time was increased from $1 \mathrm{~h}$ to $3 \mathrm{~h}$. This indicated that many arsenic compounds were released into the liquid phase products and posed a substantial risk to the environment. The effect of reaction temperature on the dissolution of HMs into liquid phase products is greater than that of residence time. In general, elevated temperature 
TABLE 2: Residual rates of HMs in the SR and WL after HTC process.

\begin{tabular}{|c|c|c|c|c|c|c|c|c|c|c|c|c|c|c|c|c|}
\hline \multirow{3}{*}{ Samples } & \multicolumn{16}{|c|}{ Percentage (\%) } \\
\hline & \multicolumn{2}{|c|}{$\mathrm{Cr}$} & \multicolumn{2}{|c|}{ Mn } & \multicolumn{2}{|c|}{$\mathrm{Ni}$} & \multicolumn{2}{|c|}{$\mathrm{Cu}$} & \multicolumn{2}{|c|}{$\mathrm{Zn}$} & \multicolumn{2}{|c|}{ As } & \multicolumn{2}{|c|}{$\mathrm{Cd}$} & \multicolumn{2}{|c|}{$\mathrm{Pb}$} \\
\hline & SR & WL & SR & $\mathrm{WL}$ & SR & WL & SR & $\mathrm{WL}$ & SR & $\mathrm{WL}$ & SR & WL & SR & WL & SR & $\mathrm{WL}$ \\
\hline SR-220-1h & 87.12 & 12.88 & 86.10 & 13.90 & 99.70 & 0.30 & 90.10 & 9.90 & 95.53 & 4.47 & 73.95 & 26.05 & 80.88 & 19.12 & 97.46 & 2.54 \\
\hline SR-220-2h & 81.71 & 18.29 & 80.08 & 19.92 & 91.48 & 8.52 & 94.16 & 5.84 & 90.27 & 9.73 & 63.78 & 36.22 & 86.68 & 13.32 & 97.62 & 2.38 \\
\hline SR-220-3h & 83.42 & 16.58 & 81.83 & 18.17 & 93.79 & 6.21 & 94.89 & 5.11 & 90.30 & 9.70 & 56.74 & 43.26 & 84.51 & 15.49 & 97.94 & 2.06 \\
\hline SR-250-1h & 91.29 & 8.71 & 79.26 & 20.74 & 95.19 & 4.81 & 92.00 & 8.00 & 80.17 & 19.83 & 46.83 & 53.17 & 77.79 & 22.21 & 99.06 & 0.94 \\
\hline SR-280-1h & 94.51 & 5.49 & 71.93 & 28.07 & 93.44 & 6.56 & 99.62 & 0.38 & 85.29 & 14.71 & 37.48 & 62.52 & 66.40 & 33.60 & 99.19 & 0.81 \\
\hline
\end{tabular}

can enhance the extraction effects of HMs and improve the degradation and transformation of organic compounds and minerals, resulting in an increase in the release rate of HMs from solid into liquid phase products $[21,34]$. However, the residual rate of $\mathrm{Cu}$ and $\mathrm{Pb}$ in the $\mathrm{SR}$ increased from $90.10 \%$ and $97.46 \%$ to $99.62 \%$ and $99.19 \%$ when the temperature was increased from $220^{\circ} \mathrm{C}$ to $280^{\circ} \mathrm{C}$. During the HTC process, $\mathrm{Cu}$ prefers to be bound to organic matter and form the $\mathrm{Cu}$ sulfide substance with high stability [17, 19, 20, 35-37]. In addition, $\mathrm{Pb}$ is easily combined with the primary minerals, such as $\mathrm{Ca}, \mathrm{Mg}$, and $\mathrm{Fe}$, through the ion exchange [38, 39]. In the case of $\mathrm{Cr}$ and $\mathrm{Cd}$, the temperature and residence time have a different effect on the residual rate in the SR. When the temperature was increased from $220^{\circ} \mathrm{C}$ to $280^{\circ} \mathrm{C}$, the residual rate of $\mathrm{Cr}$ was enhanced from $87.12 \%$ to $94.51 \%$ whilst that of $\mathrm{Cd}$ reduced from $80.88 \%$ to $66.40 \%$. In addition, as the residence time increased from $1 \mathrm{~h}$ to $3 \mathrm{~h}$, the residual rate of Cr reduced from $87.12 \%$ to $83.42 \%$, but that of $\mathrm{Cd}$ increased from $80.88 \%$ to $84.51 \%$.

As described above, the minerals in the SS have a great influence on the absorption, precipitation, and complexation of HMs. Therefore, the minerals compositions of SS before and after the HTC process need to be investigated. The experimental results are shown in Figure 3. It can be deducted that the SS and SR were mainly composed of crystalline compounds, particularly $\mathrm{Si}, \mathrm{Cu}$, and $\mathrm{Al}$ compounds. After the HTC process, the intensity at $20^{\circ}$ to $35^{\circ}$ increased significantly, indicating that the crystalline phenomenon of the HMs increased. In addition, the HMs in the SR after the HTC of SS is mainly in the form of complex compounds, and parts of their crystal structures have a resemblance [40]. According to the literature $[21,41,42], \mathrm{Fe} / \mathrm{Al}$ oxide and some inorganic minerals (clay, carbonate and phosphate, et al.) can combine and absorb the HMs through ion exchange and the surface complexation. Additionally, some organic functional groups (carboxyl and phenolic groups) and $\mathrm{S}$, $\mathrm{N}$-containing groups can reduce the migration of $\mathrm{HMs}$ in the SR via the complexation and adsorption [43]. The transformation and immobilization behaviors of HMs during the HTC process can be associated with some complicated physical-chemical processes, such as adsorption, precipitation complexation, and recombination, occurring between the HMs and the crystal lattices of SR [21, 36, 37, 44, 45]. However, detailed mechanisms of how the hydrothermal treatment affects the migration and transformation of HMs in sludge is extremely complex and still needs further investigation.

\subsection{Fractions of HMs and Environment Risk Analysis of SR}

3.3.1. Fractions and Migration Behavior of HMs during the HTC Process. Evaluation of environmental ecotoxicity of HMs predominantly depends on the chemical speciation of HMs. With reference to the bioavailability and ecotoxicity of HMs, F1 and F2 are identified as directly toxic fraction; F3 and F4 are considered as potentially toxic and nontoxic fractions, respectively. The transformation behaviors of the chemical speciation of HMs in the SS and SR after the HTC process are shown in Figure 4. The main fractions of HMs in the SS were found to be very different. $\mathrm{Cr}$ and $\mathrm{Pb}$ were mainly present in the F4 fraction (80.7\% and 95.45\%). More than $60 \% \mathrm{Ni}$ and $\mathrm{Cu}$ were in the $\mathrm{F} 3$ and $\mathrm{F} 4$ fractions, respectively. The $\mathrm{F} 1$ fraction of $\mathrm{Ni}, \mathrm{Zn}$, and $\mathrm{Cd}$ was $17.7 \%, 16.2 \%$, and $9.43 \%$, respectively, whilst they almost have no F2 fraction. Mn and As had the high concentrations in the F1 fraction, with As having more than $50 \%$ of the total, implying that there exists high potential bioavailability and ecotoxicity. From Figure 4, $\mathrm{Cr}, \mathrm{Cu}$, and $\mathrm{Pb}$ are exceptionally low at the exchangeable (F1 $<5 \%$ ) fraction. $\mathrm{Ni}, \mathrm{Zn}$, and $\mathrm{Cd}$ are also low at the exchangeable (F1 $<20 \%)$ fraction. However, $\mathrm{Mn}$ and As are high at the exchangeable ( $\mathrm{F} 1>40 \%)$ fraction.

At longer HTC residence times and higher temperatures, $\mathrm{Cr}$ and $\mathrm{Pb}$ showed no obvious changes in the F1 and F2 fraction but had a minute increase in the $\mathrm{F} 3$ fraction and slight decrease in the F4 fraction. Although $\mathrm{Cu}$ has a similar trend to $\mathrm{Cr}$ and $\mathrm{Pb}$ with regard to the change of $\mathrm{F} 1$ and $\mathrm{F} 2$ fractions, the $\mathrm{F} 3$ fraction of $\mathrm{Cu}$ sharply increased with residence time. There was also an observed initial increase followed a decrease when the temperature was increased from 220 to $280^{\circ} \mathrm{C}$. An opposite trend was observed in the F4 fraction of $\mathrm{Cu}$, indicating that the increase of the $\mathrm{F} 3$ fraction of $\mathrm{Cu}$ was mainly a result of migration from the $\mathrm{F} 4$ fraction. The Fe oxides composition favors the oxidation of copper and the combination of organic matters, resulting in the formation of $\mathrm{Cu}$-oxide complexes during the HTC process $[17,19,20,35-37]$. In the case of Mn, the HTC process showed a positive effect on the reduction of the F1 fraction when reaction temperature and residence time were increased, resulting in an increase in the F2 fraction. This suggests that the F1 fraction was converted into the F2 fraction. However, the directly toxic fractions $(\mathrm{F} 1+\mathrm{F} 2)$ reduced with an increase in the reaction temperature and residence time. The percentage of $\mathrm{Mn}$ increased in the F3 fraction with increasing temperature and residence time. Contrastingly, it reduced in the $\mathrm{F} 4$ fraction with increasing residence time, 

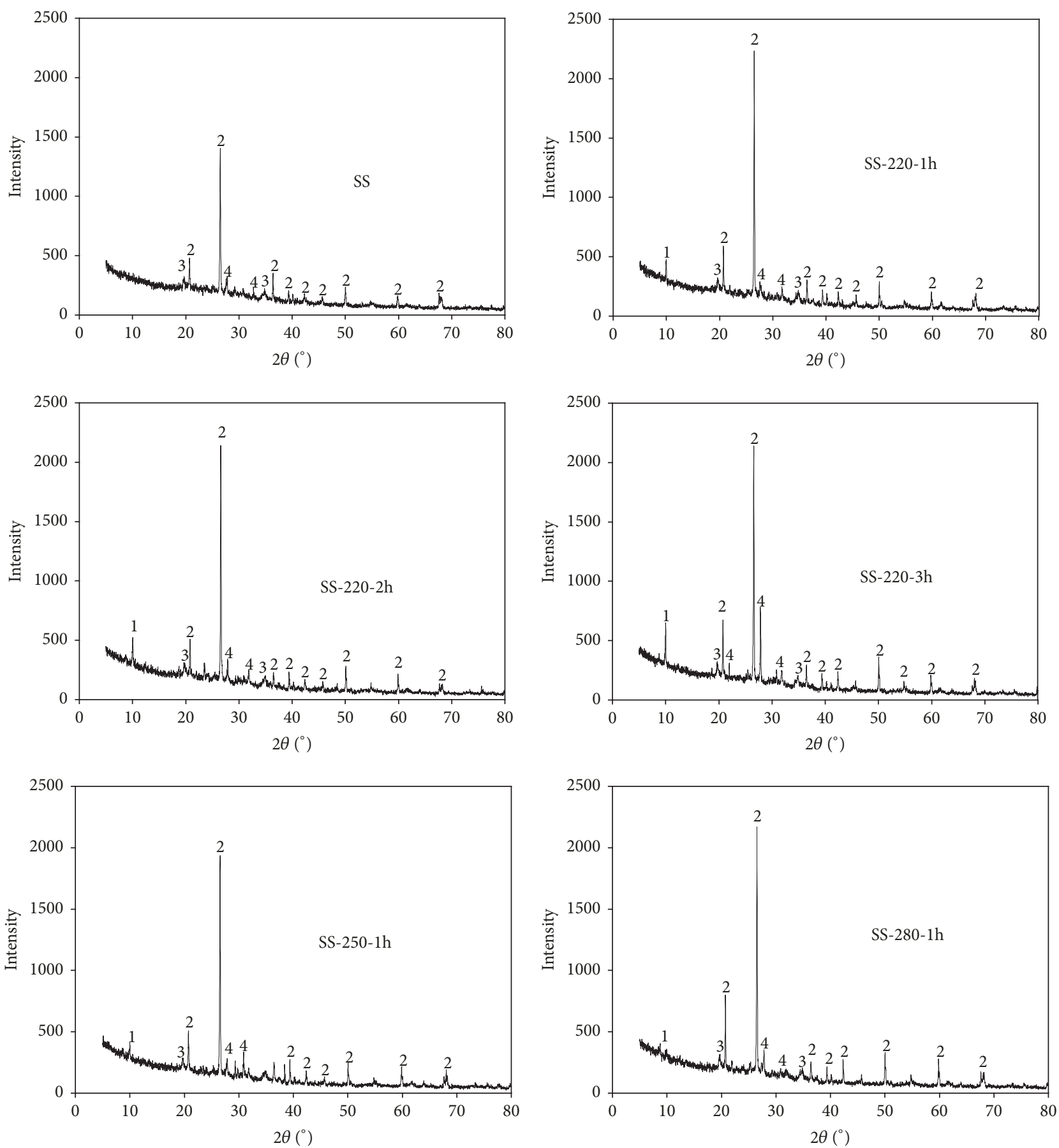

FIGURE 3: Minerals compositions of SS and SR. 1: $\mathrm{K}_{2} \mathrm{Cu}_{3}+2 \mathrm{O}\left(\mathrm{SO}_{4}\right)_{3} ; 2: \mathrm{SiO}_{2} ; 3: \mathrm{KAl}_{2} \mathrm{Si}_{3} \mathrm{AlO}_{10}(\mathrm{OH})_{2} ; 4: \mathrm{AlSO}_{4}(\mathrm{OH}) \cdot 5 \mathrm{H}_{2} \mathrm{O}$.

indicating that some of the F4 fraction of Mn was converted into the F3 fraction and increased the potential bioavailability and ecotoxicity. Similar transformation behaviors of F1 F4 fraction were observed for $\mathrm{Ni}$.

As for $\mathrm{Zn}$ and $\mathrm{Cd}$, their $\mathrm{F} 1$ fractions reduced significantly whilst their F2 and F1+F2 fractions considerably decreased. The HMs $\mathrm{F} 1+\mathrm{F} 2$ fractions increased with the reaction residence time. When the temperature was increased from 220 to $280^{\circ} \mathrm{C}$, there was an observed initial increase superseded by a reduction. The $\mathrm{Zn}$ and $\mathrm{Cd} \mathrm{F} 3$ fractions increased whilst their F4 fraction reduced with an increase in the reaction residence time and temperature, indicating that most of the F4 fraction was converted to the F3 fraction. In addition, the $\mathrm{F} 3+\mathrm{F} 4$ fractions reduced significantly with an increase of the residence time. However, no pronounced changes with temperature were observed. From the results of $\mathrm{Zn}$ and $\mathrm{Cd}$, the bioavailability and ecotoxicity increased after the HTC process, and the effect of residence time is greater than that of the reaction temperature. For As, the highest F1 fraction $(64.6 \%)$ in the SR was obtained during the HTC of SS at $220^{\circ} \mathrm{C}$ 

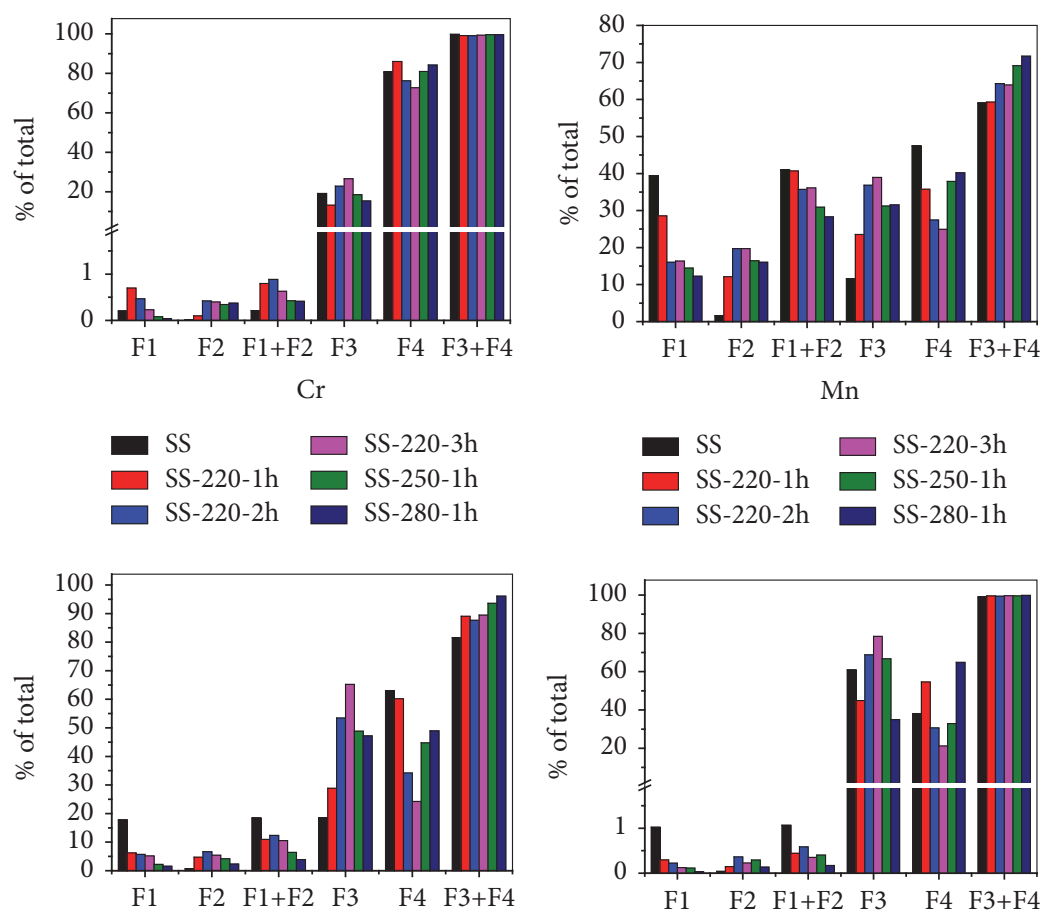

$\mathrm{Ni}$

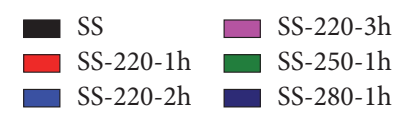

$\mathrm{Cu}$
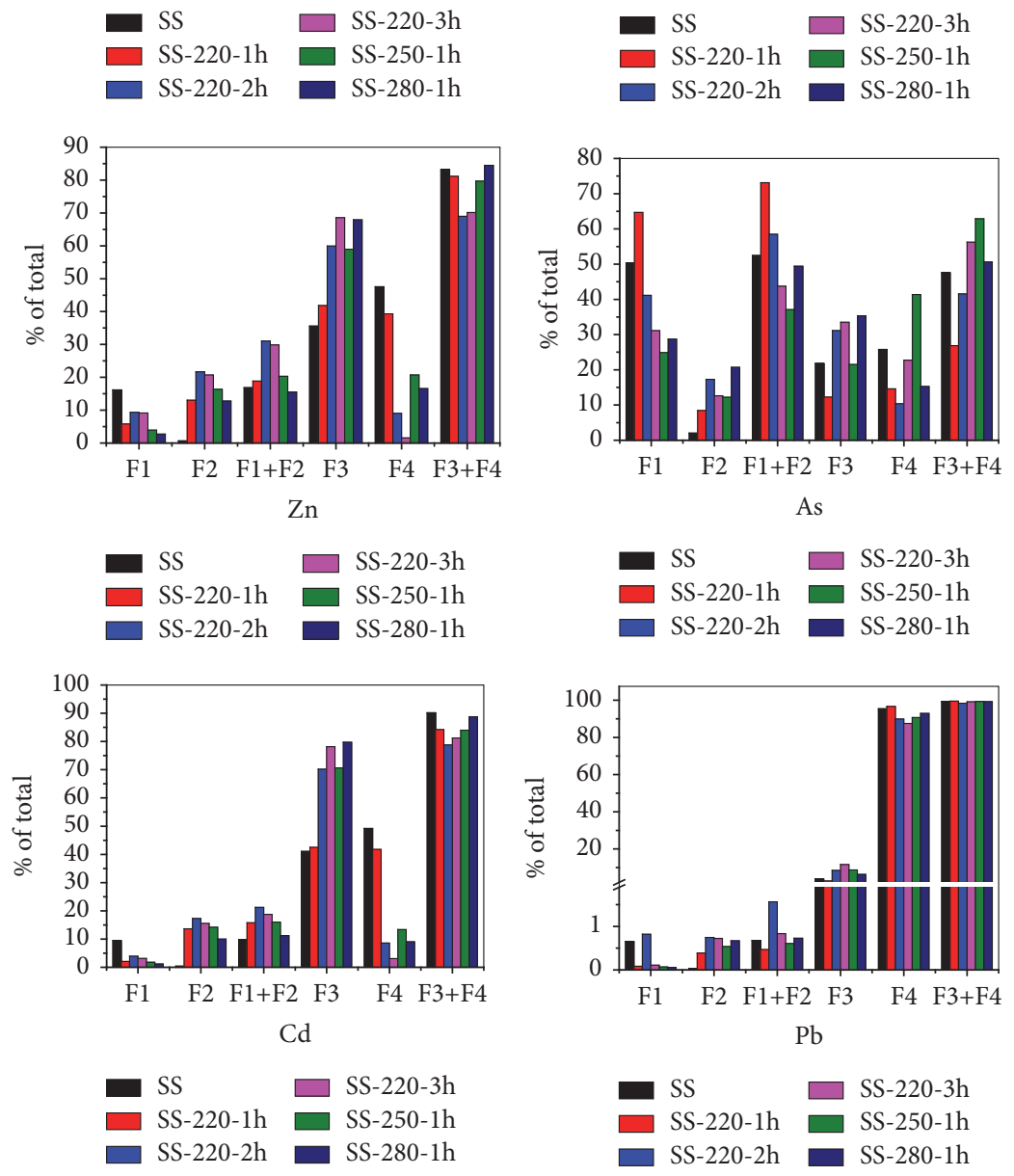

FIGURE 4: Speciation transformation behaviors of HMs in the SS before and after HTC. 
TABLE 3: Concentrations of leachable HMs in the TCLP tests (mg/kg).

\begin{tabular}{lccccccc}
\hline $\mathrm{HMs}$ & Raw SS & SS-220-1h & SS-220-2h & SS-220-3h & SS-250-1h & SS-280-1h $^{\text {Permissible limits }^{\mathrm{a}}}$ \\
\hline $\mathrm{Cr}$ & $0.11 \pm 0.00$ & $0.61 \pm 0.01$ & $0.44 \pm 0.01$ & $0.39 \pm 0.01$ & $0.09 \pm 0.00$ & $0.09 \pm 0.00$ & 5.0 \\
$\mathrm{Mn}$ & $231.06 \pm 10.67$ & $289.22 \pm 10.56$ & $293.71 \pm 12.45$ & $446.73 \pm 16.56$ & $536.53 \pm 16.78$ & $449.39 \pm 14.34$ & $-{ }^{\mathrm{b}}$ \\
$\mathrm{Ni}$ & $5.41 \pm 0.23$ & $6.73 \pm 0.25$ & $1.53 \pm 0.07$ & $1.10 \pm 0.05$ & $0.68 \pm 0.01$ & $0.72 \pm 0.01$ & 5.0 \\
$\mathrm{Cu}$ & $1.42 \pm 0.06$ & $0.41 \pm 0.01$ & $0.18 \pm 0.01$ & $0.09 \pm 0.00$ & $0.12 \pm 0.01$ & $0.04 \pm 0.00$ & $-{ }^{\mathrm{b}}$ \\
$\mathrm{Zn}$ & $30.32 \pm 1.67$ & $38.62 \pm 2.12$ & $32.18 \pm 1.68$ & $30.97 \pm 1.56$ & $13.77 \pm 0.53$ & $14.62 \pm 0.68$ & 5.0 \\
$\mathrm{As}$ & $25.57 \pm 0.48$ & $20.42 \pm 0.59$ & $12.01 \pm 0.43$ & $7.97 \pm 0.25$ & $10.34 \pm 0.38$ & $6.16 \pm 0.21$ & 5.0 \\
$\mathrm{Cd}$ & $0.05 \pm 0.00$ & $0.03 \pm 0.00$ & $0.04 \pm 0.00$ & $0.03 \pm 0.00$ & $0.03 \pm 0.00$ & $0.01 \pm 0.00$ & 1.0 \\
$\mathrm{~Pb}$ & $0.03 \pm 0.00$ & $0.02 \pm 0.00$ & $0.03 \pm 0.00$ & $0.02 \pm 0.00$ & $0.08 \pm 0.00$ & $0.01 \pm 0.00$ & 5.0 \\
\hline
\end{tabular}

(1) a: USEPA, test methods for evaluating solid waste: physical/chemical methods (SW-846).

(2) b: Not titled.

for a residence time of 1 h. Its $\mathrm{F} 1$ fraction reduced whilst its F2 fraction increased with an increase in the residence time and temperature. The F1+F2 fraction of As reduced with an increase in the residence time. With respect to increases in temperature, there was an observed increase in the F1+F2 fraction followed by a reduction. The As F3 fraction increased with residence time and temperature. These results indicate that there was practically no positive effect on the speciation transformation of As during the HTC process.

Basing on the preceding results, the weakly bound exchangeable fraction (F1) for HMs can be converted into F2 fraction as a result of the HTC process. However, HMs $(\mathrm{Cr}, \mathrm{Mn}, \mathrm{Ni}, \mathrm{Zn}, \mathrm{Cd}$, and $\mathrm{Pb}$ ) underwent a transformation from F4 fractions into F3 fractions. The F1+F2 fractions for $\mathrm{Mn}, \mathrm{Ni}$ and $\mathrm{Cu}$ significantly reduced whilst those for $\mathrm{Cr}, \mathrm{Zn}$, As, and Cd increased. The F1 and F2 fractions of $\mathrm{Mn}, \mathrm{Zn}$, As, and Cd in the SR were high, suggesting a high potential bioavailability and ecotoxicity to the environment. As such, these results indicate that the HTC process has a positive effect on the chemical speciation transformation of HMs from weakly bound fractions to the more stable fractions.

3.3.2. Leaching Characterization of SR. The leaching characteristics of HMs in the SS and SR were determined using the TLCP method [27]. The results are shown in Table 3 and Figure 5. The leached amounts of HMs from SS were 0.11, 231, $5.41,1.42,30.32,25.57,0.05$ and $0.03 \mathrm{mg} / \mathrm{kg}$ for $\mathrm{Cr}, \mathrm{Mn}, \mathrm{Ni}, \mathrm{Cu}$, $\mathrm{Zn}, \mathrm{As}, \mathrm{Cd}$ and $\mathrm{Pb}$, respectively. The leached amounts of $\mathrm{Ni}$, $\mathrm{Zn}$ and As were higher than the permissible limits (USEPA, SW-846) and therefore exhibited potential toxicity. When the reaction temperature and residence time were increased, the leached amounts of $\mathrm{Ni}, \mathrm{Cu}, \mathrm{Zn}$ and As reduced significantly. However, the amount of Mn highly increased and no obvious changes were observed for $\mathrm{Cr}, \mathrm{Cd}$ and $\mathrm{Pb}$. In addition, the concentrations of leachable HMs in SS-220-3h were higher than those in SS-280-1h, indicating that the influence of reaction temperature on the reduction of leachable HMs was greater than that of residence time. Higher reaction temperatures contribute to the combination of HMs with crystal lattices of SR and enhance the immobilization of HMs [21, 40, 44, 45]. Briefly, the HTC process exhibited a significant reduction of the leaching risk of HMs. In contrast, the leached amounts of $\mathrm{Zn}$ and As were still high $(14.61 \mathrm{mg} / \mathrm{kg}$

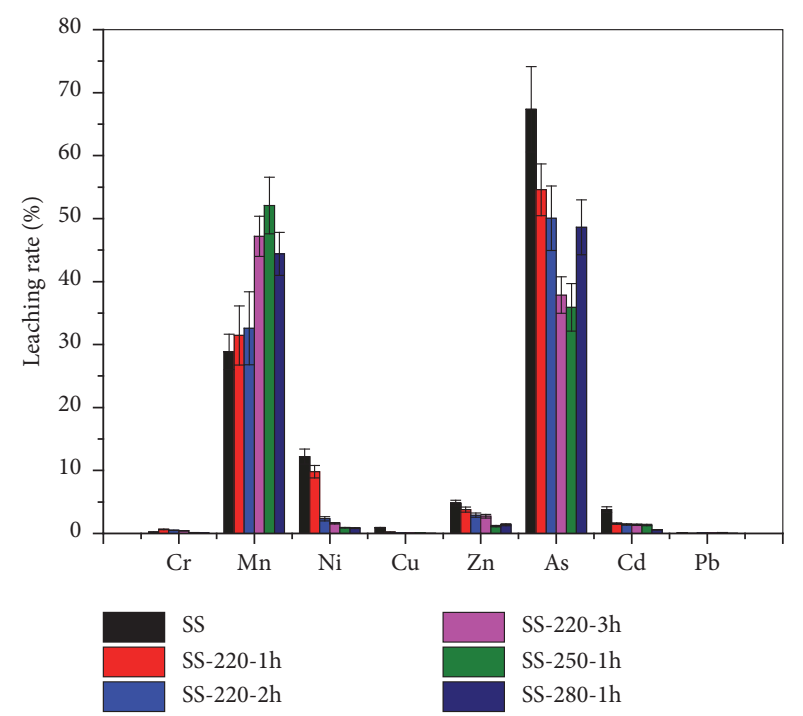

Figure 5: Leaching rates of HMs in the TCLP tests.

and $6.16 \mathrm{mg} / \mathrm{kg}$, respectively) and therefore showed a high leaching risk to the environment.

The leaching rate of HMs from SS and SR are shown in Figure 5. The leaching rate is defined as the ratio of the amount of a heavy metal in the leachate to the total amount of this heavy metal $[17,19,46]$.

With an increase in the reaction temperature and residence time, the leaching rate of all HMs (except Mn and As) in the SR decreased significantly and almost exhibited no leaching rate. The leaching rate of As reduced when residence time was increased. However, the leaching rate of As first reduced and then increased when the temperature was increased from 220 to $280^{\circ} \mathrm{C}$. The As leaching rate was close $50 \%$ at a reaction temperature of $280^{\circ} \mathrm{C}$ for a residence time of $1 \mathrm{~h}$. This exhibits a high leaching risk to the environment. As shown in Table 3 and Figure 5, the leachable fractions of HMs in the SR endured a significant reduction as a result of the HTC process. This observation however does not include As and Mn which had high leaching rates.

3.4. Immobilization Behaviors of HMs in the Combustion Residual. The immobilization behaviors of HMs during the 
TABLE 4: Concentrations of HMs in the combustion residual (mg/kg).

\begin{tabular}{lcccccccc}
\hline Samples & $\mathrm{Cr}$ & $\mathrm{Mn}$ & $\mathrm{Ni}$ & $\mathrm{Cu}$ & $\mathrm{Zn}$ & $\mathrm{As}$ & $\mathrm{Cd}$ \\
\hline SS & $156.50 \pm 5.56$ & $1160.75 \pm 65.87$ & $88.61 \pm 4.89$ & $382.20 \pm 15.67$ & $1448.33 \pm 70.45$ & $62.36 \pm 2.56$ & $3.35 \pm 0.08$ & $111.87 \pm 3.32$ \\
SS-220-1h & $200.90 \pm 6.78$ & $1338.55 \pm 77.34$ & $126.63 \pm 7.45$ & $580.82 \pm 18.56$ & $2026.21 \pm 68.62$ & $62.58 \pm 2.03$ & $4.62 \pm 0.10$ & $168.50 \pm 5.25$ \\
SS-220-2h & $182.66 \pm 6.68$ & $1345.87 \pm 72.56$ & $118.05 \pm 6.45$ & $505.83 \pm 12.05$ & $1950.73 \pm 55.24$ & $44.65 \pm 1.89$ & $4.66 \pm 0.11$ & $147.99 \pm 3.98$ \\
SS-220-3h & $187.80 \pm 8.56$ & $1425.18 \pm 65.45$ & $125.41 \pm 5.23$ & $531.88 \pm 10.78$ & $2010.28 \pm 69.46$ & $41.61 \pm 1.01$ & $4.63 \pm 0.09$ & $152.88 \pm 4.23$ \\
SS-250-1h & $184.07 \pm 10.56$ & $1350.55 \pm 75.78$ & $118.88 \pm 6.54$ & $531.64 \pm 11.34$ & $1964.51 \pm 51.67$ & $41.36 \pm 1.56$ & $4.55 \pm 0.13$ & $152.55 \pm 4.01$ \\
SS-280-1h & $219.89 \pm 11.45$ & $1356.32 \pm 68.67$ & $124.50 \pm 5.45$ & $580.29 \pm 15.67$ & $1972.96 \pm 75.34$ & $38.39 \pm 1.12$ & $4.69 \pm 0.08$ & $153.34 \pm 4.23$ \\
\hline
\end{tabular}

TABLE 5: Residual rates of HMs in the combustion residual (\%).

\begin{tabular}{lcccccccc}
\hline Samples & $\mathrm{Cr}$ & $\mathrm{Mn}$ & $\mathrm{Ni}$ & $\mathrm{Cu}$ & $\mathrm{Zn}$ & $\mathrm{As}$ & $\mathrm{Cd}$ \\
\hline Raw SS & 87.36 & 74.97 & 90.69 & 72.16 & 88.47 & 85.09 & 91.72 & 75.31 \\
SS-220-1h & 90.15 & 84.84 & 91.70 & 79.13 & 86.65 & 87.57 & 91.87 & 79.59 \\
SS-220-2h & 91.12 & 92.29 & 92.39 & 80.07 & 88.60 & 85.02 & 92.23 \\
SS-220-3h & 90.09 & 92.78 & 92.95 & 79.26 & 90.12 & 88.22 & 91.13 & 81.13 \\
SS-250-1h & 92.53 & 84.80 & 95.95 & 75.14 & 90.31 & 91.50 & 92.08 \\
SS-280-1h & 93.88 & 88.46 & 93.28 & 78.51 & 92.03 & 92.86 & 92.61 \\
\hline
\end{tabular}

combustion of SR produced from the HTC of SS were analyzed. The concentrations of HMs in the combustion residual are shown in Table 4 . Compared to the combustion of SS, the respective amounts of HMs (except As) in the combustion residual of SR increased. In addition, the amounts of HMs in the combustion residual are higher than that in the SS and SR (Figure 2). This indicates that most of HMs accumulated in the combustion residual. However, as for As, the concentration changed considerably from 62.58 $\mathrm{mg} / \mathrm{kg}$ to $38.39 \mathrm{mg} / \mathrm{kg}$ when the HTC SR changed from "SS220-1h" to "SS-280-1h". Arsenic has a low boiling point and therefore exhibits volatile and gasification properties [47]. Consequently, it can easily be gasified during the combustion process. In addition, some inorganic compounds ( $\mathrm{Ca}, \mathrm{Al}$, and Fe compounds) can provide chemical reactive sites of arsenic and enhance the complexation and absorption of arsenic by forming various arsenates in the fly ash and solid residual [48-51]. From Table 4, the concentrations of HMs in the combustion residual have minimal pronounced changes even when the HTC reaction temperature and residence time were varied. Although the HTC process was carried out at different reaction conditions, the chemical compositions of SR tend to be stable and the crystal lattices of HMs are similar [40]. The residual rates of $\mathrm{HMs}$ after the combustion of SR produced from the HTC of SS are presented in Table 5. As seen from Table 5, the residual rates of all HMs were more than $70 \%$, particularly for $\mathrm{Cr}, \mathrm{Ni}, \mathrm{Zn}$, and $\mathrm{Cd}$ which had more than $90 \%$ residual rates. With increasing HTC reaction temperature and residence time, the residual rates of $\mathrm{HMs}$ (except $\mathrm{Pb}$ ) in the combustion residual of SR increased, indicating that the HTC process promotes the immobilization of HMs in the combustion solid residual.

\section{Conclusions}

The transformation behaviors of $\mathrm{Cr}, \mathrm{Mn}, \mathrm{Ni}, \mathrm{Cu}, \mathrm{Zn}, \mathrm{As}, \mathrm{Cd}$, and $\mathrm{Pb}$ in the SS during the HTC process combined with combustion were investigated. Most of the HMs accumulated in the SR during HTC and combustion process, respectively. However, the concentration and residual rate of As in the SR reduced with an increase in the HTC reaction temperature and residence time, implying that many arsenic compounds are released into the liquid phase products. After the HTC process, the weakly bonded fractions of HMs migrated to the more stable fraction. However, the exchangeable and reducible fractions of $\mathrm{Mn}, \mathrm{Zn}$, As, and $\mathrm{Cd}$ in SR were remarkably high and presented an elevated risk to the environment. The leaching characteristics of HMs in the SR showed a significant improvement. Contrastingly, the leached amounts of $\mathrm{Zn}$ and As were still high and exceeded the permissible limits. The contents of HMs in the combustion residual were higher than those in the SS and SR. The residual rates of almost all the HMs in the combustion residual of SR produced from the HTC of SS increased with increasing HTC temperature and residence time, indicating that the HTC process promotes the immobilization of HMs in the combustion process.

\section{Data Availability}

The data used to support the findings of this study are available from the corresponding author upon request.

\section{Conflicts of Interest}

There are no conflicts of interest regarding the publication of this paper.

\section{Acknowledgments}

The authors would like to thank Dr. Marcos Millan, Department of Chemical Engineering, Imperial College London, UK, for his good suggestion and professional advice. This work was supported by the National Natural Science Foundation of China (51606103 and 51206028). 


\section{References}

[1] I. Fonts, G. Gea, M. Azuara, J. Ábrego, and J. Arauzo, "Sewage sludge pyrolysis for liquid production: a review," Renewable \& Sustainable Energy Reviews, vol. 16, no. 5, pp. 2781-2805, 2012.

[2] Y. Zhai, X. Liu, Y. Zhu et al., "Hydrothermal carbonization of sewage sludge: The effect of feed-water $\mathrm{pH}$ on fate and risk of heavy metals in hydrochars," Bioresource Technology, vol. 218, pp. 183-188, 2016.

[3] N. Gao, C. Quan, B. Liu, Z. Li, C. Wu, and A. Li, "Continuous Pyrolysis of Sewage Sludge in a Screw-Feeding Reactor: Products Characterization and Ecological Risk Assessment of Heavy Metals," Energy \& Fuels, vol. 31, no. 5, pp. 5063-5072, 2017.

[4] W. Rulkens, "Sewage sludge as a biomass resource for the production of energy: Overview and assessment of the various options," Energy \& Fuels, vol. 22, no. 1, pp. 9-15, 2008.

[5] W. H. Rulkens and J. D. Bien, "Recovery of energy from sludge - Comparison of the various options," Water Science and Technology, vol. 50, no. 9, pp. 213-221, 2004.

[6] L. Wang, A. Li, and Y. Chang, "Hydrothermal treatment coupled with mechanical expression at increased temperature for excess sludge dewatering: Heavy metals, volatile organic compounds and combustion characteristics of hydrochar," Chemical Engineering Journal, vol. 297, pp. 1-10, 2016.

[7] G. Mininni, R. Di Bartolo Zuccarello, V. Lotito, L. Spinosa, and A. C. Di Pinto, "A design model of sewage sludge incineration plants with energy recovery," Water Science and Technology, vol. 36, no. 11, pp. 211-218, 1997.

[8] T. Namioka, Y. Morohashi, R. Yamane, and K. Yoshikawa, "Hydrothermal Treatment of Dewatered Sewage Sludge Cake for Solid Fuel Production," Journal of Environment and Engineering, vol. 4, no. 1, pp. 68-77, 2009.

[9] C. Areeprasert, D. Ma, P. Prayoga, and K. Yoshikawa, "A Review on Pilot-Scale Applications of Hydrothermal Treatment for Upgrading Waste Materials," International Journal of Environmental Science and Development, vol. 7, no. 6, pp. 425-430, 2016.

[10] M. Yan, B. Prabowo, Z. Fang, W. Chen, Z. Jiang, and Y. $\mathrm{Hu}$, "Effect of hydrothermal treatment temperature on the properties of sewage sludge derived solid fuel," International Journal of Renewable Energy Development (IJRED), vol. 4, no. 3, 2015.

[11] P. Zhao, Y. Shen, S. Ge, and K. Yoshikawa, "Energy recycling from sewage sludge by producing solid biofuel with hydrothermal carbonization," Energy Conversion and Management, vol. 78, pp. 815-821, 2014.

[12] M. Escala, T. Zumbühl, C. Koller, R. Junge, and R. Krebs, "Hydrothermal carbonization as an energy-efficient alternative to established drying technologies for sewage sludge: A feasibility study on a laboratory scale," Energy \& Fuels, vol. 27, no. 1, pp. 454-460, 2013.

[13] J. H. Zhang, Q. Luo, Q. M. Lin, X. X. Zhao, G. T. Li, and G. F. $\mathrm{Wu}$, "Characteristics of wastewater from municipal sludge after hydrothermal carbonization treatment," Chinese Journal of Envionmental Engineering, vol. 7, pp. 3363-3368, 2003.

[14] P. Zhao, H. Chen, S. Ge, and K. Yoshikawa, "Effect of the hydrothermal pretreatment for the reduction of no emission from sewage sludge combustion," Applied Energy, vol. 111, pp. 199-205, 2013.

[15] E. Danso-Boateng, G. Shama, A. D. Wheatley, S. J. Martin, and R. G. Holdich, "Hydrothermal carbonisation of sewage sludge: Effect of process conditions on product characteristics and methane production," Bioresource Technology, vol. 177, pp. 318$327,2015$.

[16] L. Appels, J. Degrève, B. Van der Bruggen, J. Van Impe, and R. Dewil, "Influence of low temperature thermal pre-treatment on sludge solubilisation, heavy metal release and anaerobic digestion," Bioresource Technology, vol. 101, no. 15, pp. 5743$5748,2010$.

[17] W. Shi, C. Liu, D. Ding et al., "Immobilization of heavy metals in sewage sludge by using subcritical water technology," Bioresource Technology, vol. 137, pp. 18-24, 2013.

[18] W. Shi, C. Liu, Y. Shu, C. Feng, Z. Lei, and Z. Zhang, "Synergistic effect of rice husk addition on hydrothermal treatment of sewage sludge: Fate and environmental risk of heavy metals," Bioresource Technology, vol. 149, pp. 496-502, 2013.

[19] X. Wang, C. Li, B. Zhang, J. Lin, Q. Chi, and Y. Wang, "Migration and risk assessment of heavy metals in sewage sludge during hydrothermal treatment combined with pyrolysis," Bioresource Technology, vol. 221, pp. 560-567, 2016.

[20] X. Xu and E. Jiang, "Treatment of urban sludge by hydrothermal carbonization,” Bioresource Technology, vol. 238, pp. 182-187, 2017.

[21] H.-J. Huang and X.-Z. Yuan, "The migration and transformation behaviors of heavy metals during the hydrothermal treatment of sewage sludge," Bioresource Technology, vol. 200, pp. 991-998, 2016.

[22] C. He, A. Giannis, and J.-Y. Wang, "Conversion of sewage sludge to clean solid fuel using hydrothermal carbonization: Hydrochar fuel characteristics and combustion behavior," Applied Energy, vol. 111, pp. 257-266, 2013.

[23] G. K. Parshetti, Z. Liu, A. Jain, M. P. Srinivasan, and R. Balasubramanian, "Hydrothermal carbonization of sewage sludge for energy production with coal," Fuel, vol. 111, pp. 201-210, 2013.

[24] C. Areeprasert, P. Chanyavanich, D. Ma, Y. Shen, and K. Yoshikawa, "Effect of hydrothermal treatment on co-combustion of paper sludge with coal: thermal behavior, NO emissions, and slagging/fouling tendency," Biofuels, vol. 8, no. 2, pp. 187196, 2017.

[25] J. Yu, M. Guo, X. Xu, and B. Guan, “The role of temperature and $\mathrm{CaCl} 2$ in activated sludge dewatering under hydrothermal treatment." Water Research, vol. 50, pp. 10-17, 2014.

[26] G. Rauret, J. F. López-Sánchez, A. Sahuquillo et al., "Improvement of the BCR three step sequential extraction procedure prior to the certification of new sediment and soil reference materials," Journal of Environmental Monitoring, vol. 1, no. 1, pp. 57-61, 1999.

[27] A. Nair, A. A. Juwarkar, and S. Devotta, "Study of speciation of metals in an industrial sludge and evaluation of metal chelators for their removal," Journal of Hazardous Materials, vol. 152, no. 2, pp. 545-553, 2008.

[28] L. Wang, L. Zhang, and A. Li, "Hydrothermal treatment coupled with mechanical expression at increased temperature for excess sludge dewatering: Influence of operating conditions and the process energetics," Water Research, vol. 65, pp. 85-97, 2014.

[29] A. Funke and F. Ziegler, "Hydrothermal carbonization of biomass: a summary and discussion of chemical mechanisms for process engineering," Biofuels, Bioproducts and Biorefining, vol. 4, no. 2, pp. 160-177, 2010.

[30] X. Yuan, H. Huang, G. Zeng et al., “Total concentrations and chemical speciation of heavy metals in liquefaction residues of sewage sludge," Bioresource Technology, vol. 102, no. 5, pp. 41044110, 2011. 
[31] L. Leng, X. Yuan, H. Huang, H. Jiang, X. Chen, and G. Zeng, "The migration and transformation behavior of heavy metals during the liquefaction process of sewage sludge," Bioresource Technology, vol. 167, pp. 144-150, 2014.

[32] H.-J. Huang and X.-Z. Yuan, "Recent progress in the direct liquefaction of typical biomass," Progress in Energy and Combustion Science, vol. 49, pp. 59-80, 2015.

[33] L. Li, Z. R. Xu, C. Zhang, J. Bao, and X. Dai, "Quantitative evaluation of heavy metals in solid residues from sub- and super-critical water gasification of sewage sludge," Bioresource Technology, vol. 121, pp. 169-175, 2012.

[34] N. Peng, Y. Li, T. Liu, Q. Lang, C. Gai, and Z. Liu, "Polycyclic Aromatic Hydrocarbons and Toxic Heavy Metals in Municipal Solid Waste and Corresponding Hydrochars," Energy \& Fuels, vol. 31, no. 2, pp. 1665-1671, 2017.

[35] M. R. Lasheen and N. S. Ammar, "Assessment of metals speciation in sewage sludge and stabilized sludge from different Wastewater Treatment Plants, Greater Cairo, Egypt," Journal of Hazardous Materials, vol. 164, no. 2-3, pp. 740-749, 2009.

[36] Y. Zhou, Z. Zhang, J. Zhang, and S. Xia, "Understanding key constituents and feature of the biopolymer in activated sludge responsible for binding heavy metals," Chemical Engineering Journal, vol. 304, pp. 527-532, 2016.

[37] J. Laurent, M. Casellas, H. Carrère, and C. Dagot, "Effects of thermal hydrolysis on activated sludge solubilization, surface properties and heavy metals biosorption," Chemical Engineering Journal, vol. 166, no. 3, pp. 841-849, 2011.

[38] M. N. Islam and J.-H. Park, "Immobilization and reduction of bioavailability of lead in shooting range soil through hydrothermal treatment," Journal of Environmental Management, vol. 191, pp. 172-178, 2017.

[39] J. W. C. Wong, K. Li, K. Fang, and D. C. Su, “Toxicity evaluation of sewage sludges in Hong Kong," Environment International, vol. 27, no. 5, pp. 373-380, 2001.

[40] R. Ma, Y. Zhou, and L. Fang, "International Conference on Advances in Energy and Environmental Science (ICAEES," in Proceedings of the International Conference on Advances in Energy and Environmental Science (ICAEES, Zhuhai, China, 2015.

[41] D. S. Apul, K. H. Gardner, T. T. Eighmy, A.-M. Fällman, and R. N. J. Comans, "Simultaneous application of dissolution/ precipitation and surface complexation/surface precipitation modeling to contaminant leaching," Environmental Science \& Technology, vol. 39, no. 15, pp. 5736-5741, 2005.

[42] A. A. Rouff, E. J. Elzinga, R. J. Reeder, and N. S. Fisher, "X-ray Absorption Spectroscopic Evidence for the Formation of $\mathrm{Ph}(\mathrm{II})$ Inner-Sphere Adsorption Complexes and Precipitates at the Calcite-Water Interface," Environmental Science \& Technology, vol. 38, no. 6, pp. 1700-1707, 2004.

[43] L. K. Koopal, T. Saito, J. P. Pinheiro, and W. H. Van Riemsdijk, "Ion binding to natural organic matter: General considerations and the NICA-Donnan model," Colloids and Surfaces A: Physicochemical and Engineering Aspects, vol. 265, no. 1-3, pp. 40-54, 2005.

[44] C. Wang, N. Zhu, Y. Wang, and F. Zhang, "Co-detoxification of transformer oil-contained PCBs and heavy metals in medical waste incinerator fly ash under sub- and supercritical water," Environmental Science \& Technology, vol. 46, no. 2, pp. 10031009, 2012.

[45] H. Pan, "Effects of liquefaction time and temperature on heavy metal removal and distribution in liquefied CCA-treated wood sludge," Chemosphere, vol. 80, no. 4, pp. 438-444, 2010.
[46] H. Huang, X. Yuan, G. Zeng et al., "Quantitative evaluation of heavy metals' pollution hazards in liquefaction residues of sewage sludge," Bioresource Technology, vol. 102, no. 22, pp. 10346-10351, 2011.

[47] S. Van Wesenbeeck, W. Prins, F. Ronsse, and M. J. Antal, "Sewage sludge carbonization for biochar applications. Fate of heavy metals," Energy \& Fuels, vol. 28, no. 8, pp. 5318-5326, 2014.

[48] Y. Zhao, Q. Ren, and Y. Na, "Speciation transformation of arsenic during municipal sewage sludge incineration with cotton stalk as additive," Fuel, vol. 202, pp. 541-546, 2017.

[49] H. Yao and I. Naruse, "Control of trace metal emissions by sorbents during sewage sludge combustion," Proceedings of the Combustion Institute, vol. 30, pp. 3009-3016, 2005.

[50] Y. Zhao, J. Zhang, W. Huang et al., "Arsenic emission during combustion of high arsenic coals from Southwestern Guizhou, China," Energy Conversion and Management, vol. 49, no. 4, pp. 615-624, 2008.

[51] H. Liu, C. Wang, C. Zou, Y. Zhang, and J. Wang, "Simultaneous volatilization characteristics of arsenic and sulfur during isothermal coal combustion," Fuel, vol. 203, pp. 152-161, 2017. 


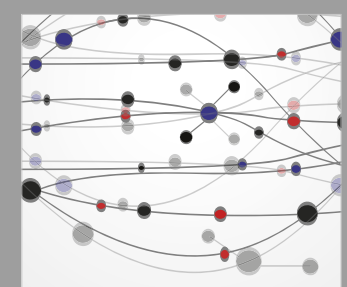

The Scientific World Journal
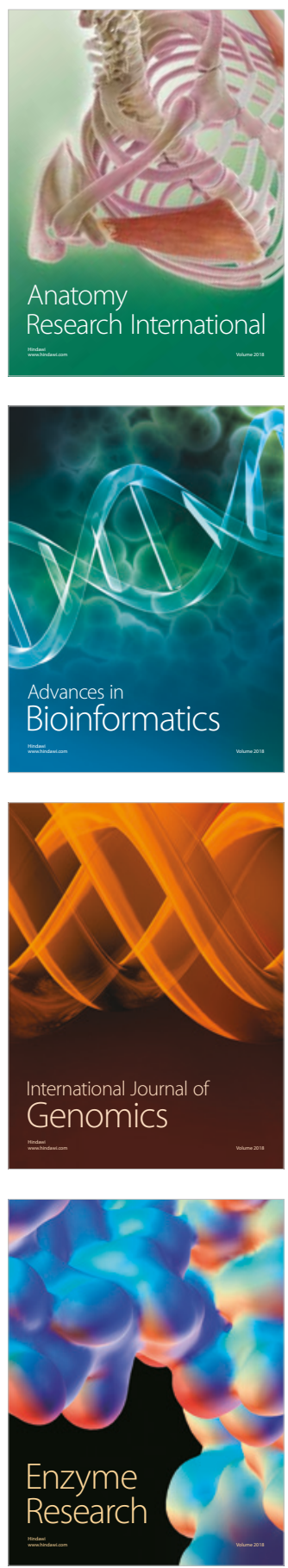
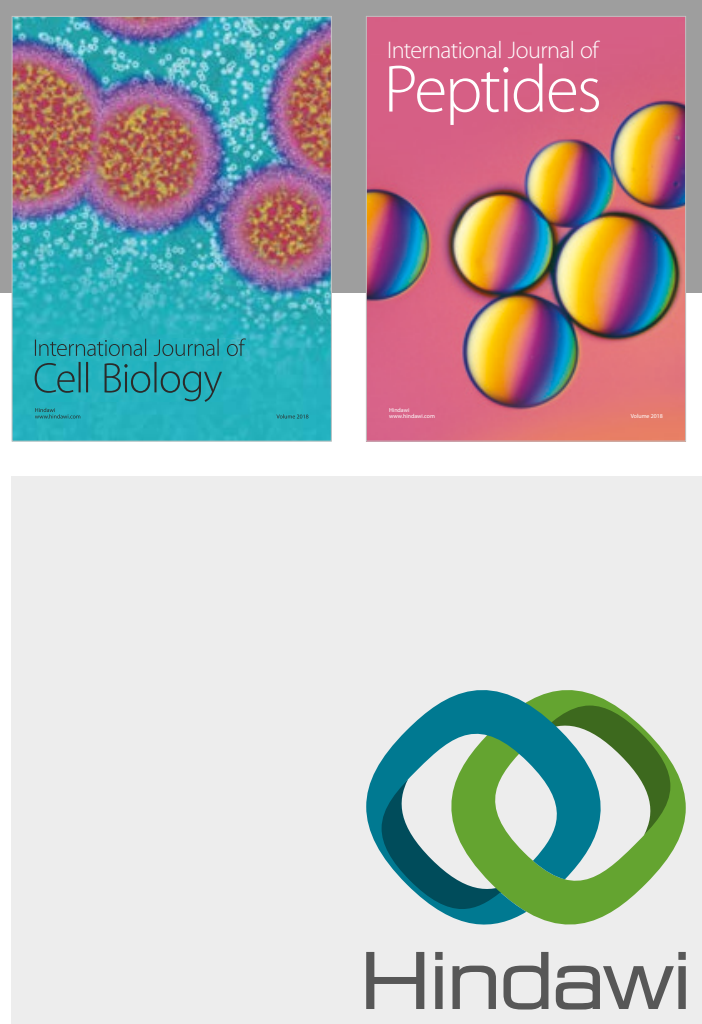

Submit your manuscripts at

www.hindawi.com
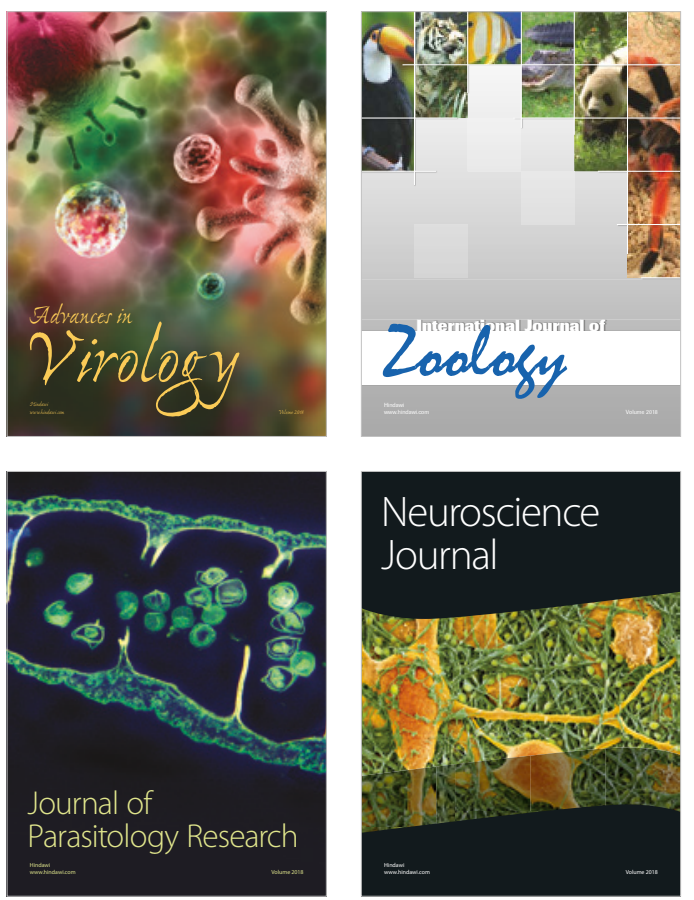
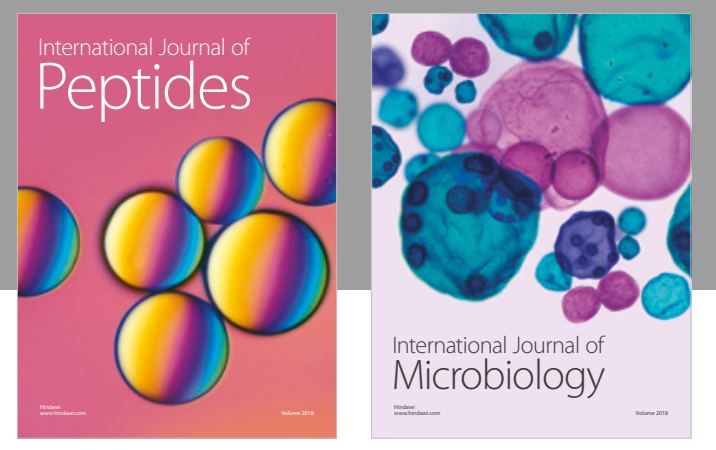

nternational Journal of Microbiology
Journal of
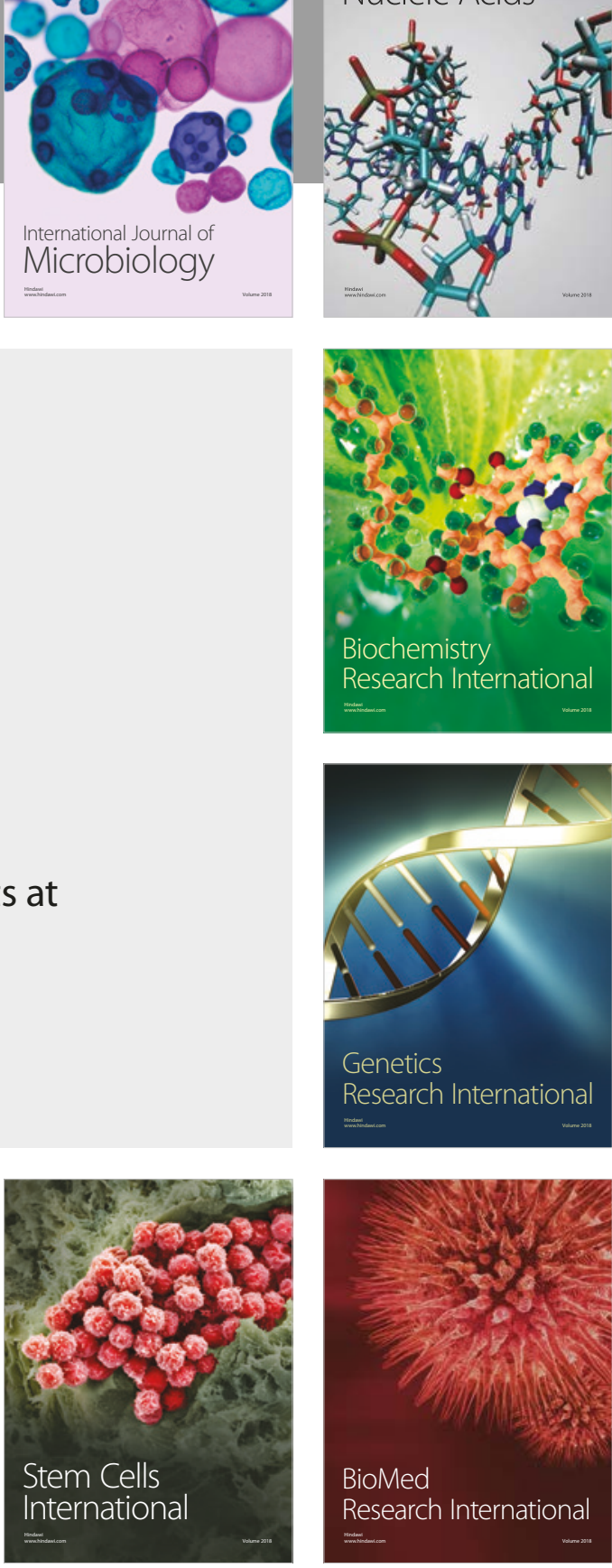
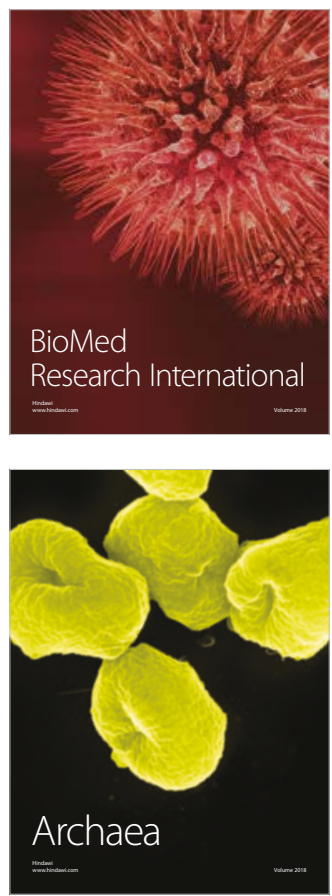